\title{
Evaluation of Specialty Training Level of Emergency Medicine Residents
}

\author{
(1) Kazım Ersin Altınsoy' ${ }^{1}$, (1) Ataman Köse ${ }^{1}$, (1) Yücel Uysal ${ }^{2}$, (1) Seyran Bozkurt Babuș ${ }^{1}$, (1) Semra Erdoğan ${ }^{3}$ \\ 1Department of Emergency Medicine, Mersin University Faculty of Medicine, Mersin, Turkey \\ 2Department of Family Medicine, Mersin University Faculty of Medicine, Mersin, Turkey \\ ${ }^{3}$ Department of Biostatistics and Medical Informatics, Mersin University Faculty of Medicine, Mersin, Turkey
}

\begin{abstract}
Aim: This study aimed to determine the quality perceptions and factors affecting emergency medicine specialty training using a questionnaire answered by emergency department (ED) residents.

Materials and Methods: This study was conducted at the ED between February 2019 and June 2019. ED residents working at state universities, foundation universities, and educational research hospitals were included in the study. The first three survey questions aimed to reveal the characteristics of the participants. Other questions were focused on the application and practice of residency.

Results: Three hundred thirty-six residents were included in this study. $85.1 \%$ of the residents worked at public universities. Two hundred and fifty $(74.4 \%)$ participants declared that they had between four to six instructors. $96.3 \%$ stated that training meetings were held every week, 32.2\% stated that education was adequate, and $85.9 \%$ did not apply for a resident exam in their clinics. While there was a difference between patient care $(p=0.006)$ and research $(p<0.001)$ in the departments or institutions that received training, there was no significant difference in terms of education $(p=0.238)$. When the numerical adequacy of the educational staff was evaluated, the quality perceptions of the educational staff and the education received in the institution affected each other $(p<0.001)$.

Conclusion: It was concluded that a standard residency program was needed and the capacity, infrastructure characteristics, and training staff of the training institutions should be reviewed and properly regulated.
\end{abstract}

Keywords: Emergency medicine, medical education, resident

\section{Introduction}

Specialty training in medicine is an organized and comprehensive training program offered to the specialty training student (resident and research assistant) under guidance and supervision. The adequacy of the training period, rotation programs in subjects that are lacking, and underachieved are the elements that enrich the quality of the training. Feedback on trainers and residents is also a very important part of the training (1). In the studies, the factor affecting residency training was divided into two groups: factors directly related to training (such as instructor qualification, time allocated to training, feedback) and situations that caused the candidate of emergency medicine to spend unproductive time (2). Many medicine branches try to cover their deficiencies and deficiencies through their federations or associations (3). Written feedback and competency-based expertise training and evaluation are only possible with the establishment of an effective and standard curriculum. In recent years, these efforts in medical specialty training are not only performed in Turkey, but also in many countries in the areas of pre-graduation, post-graduation, and continuing medical education (1). Furthermore, the lack of a standard training curriculum will result in the inability to provide equal education among residents and the inability to take the proficiency exam provided for by the medical specialties 
statute (1). Efforts to achieve standardization at the national level in specialty training are increasing in our country. The realization and implementation of national education curricula, proficiency exams, and supervisory boards will accelerate this transformation (4).

It is important that the training provided in the EDs of the university hospitals, educational research hospitals, and Foundation University Hospitals providing specialty training in ED is qualified. In order to train qualified experts, training planning needs to be done in advance by the experts of the subject, and the educational infrastructure of the institutions must be sufficient. This study aims to analyze the educational status of emergency department residents (EDR) in our country and to reveal their problems. Thus, data to contribute to medical trainers and curriculum developers were summarized. In this context, both perception and fact-oriented questions were asked to the residents, and the results were tried to be presented with statistical evaluations. By investigating the characteristics of emergency medicine specialty training, a study was aimed to help to provide better training and establish a standard training program.

\section{Materials and Methods}

\section{Type of Research}

This study was conducted to evaluate the level of specialty training of EDR's working in emergency departments throughout Turkey between 01 February 2019-30 June 2019 at Mersin University Faculty of Medicine Department of Emergency Medicine. The study was conducted after the approval of the Clinical Research Ethics Committee of Mersin University Rectorate (dated 09.01.2017 and numbered 2019/03). The survey method was used to provide data to the research.

\section{Universe of Research}

EDR's working in State University Hospitals, training and research hospitals, and foundation university hospitals where emergency medicine expertise training is provided within the borders of Turkey were included in the study. It consists of 456 EDR physicians who are on the register of emergency medical professionals associations, who have received training in university hospitals, private foundation hospitals, and educational research hospitals. A total of 456 EDR were included in the study, including 266 from university hospitals, 138 from educational research hospitals, and 52 from foundation universities. According to this information, the sample size was planned in two stages to best predict the universe. In the first phase, universities and educational research hospitals in Turkey are divided into layers based on random sampling methods and institutions. Then emergency medical residents were randomly identified on each layer and from each institution. Sample numbers were determined by calculating $20 \%$ estimate of missing subjects. Accordingly, a total of 364 ED were scheduled to be included in the study.

\section{Data Collection Tools}

On 456 EDR internet-based survey sites registered in ED associations (www.survey.com) the pre-prepared questionnaire was filled out by e-mail or by hand. Those who completed the survey form incomplete or incorrect were excluded from the study from EDR physicians who returned by e-mail or by hand. A total of 348 surveys were evaluated. The survey results, either by e-mail or by hand, were examined individually by the researcher and recorded in a pre-prepared data form.

The survey consists of 20 questions. The first three survey questions are intended to reveal participant characteristics. Other questions are directed at the practice and practice of resident training. Participants were asked two different types of questions, closed to interpretation (perception) and open to interpretation (perception). 1-7, 9, 10, 13 and 15. questions closed to interpretation $8,11,12,14,16-20$. the questions are open to interpretation. 8, 11, 12, 14, 16, 19 and 20. the ingredients are prepared on a Likert scale. Likert items are rated between 1-5. 1 indicates super negative and 5 indicates super positive perception.

\section{Statistical Analysis}

Normality controls for continuous measurements were tested with the Shapiro-Wilk method. The student test was used for differences in age averages in terms of sexes. The Levene test was used for homogeneity of the variances. One-way ANOVA test was used for cases where the variances were homogeneous, and Welch test was used for cases where the variances were heterogeneous, for differences between institutions in terms of service, education, and research rates, The Bonferroni test was used when the variances were homogeneous, and the GamesHowell test was used when the variances were heterogeneous, for binary comparisons. Mean and standard deviation values were calculated as descriptive statistics. Pearson chi-square and likelihood ratio chi-square tests were used to compare categorical data. Number and percentage values were calculated as descriptive statistics. $\mathrm{P}<0.05$ was accepted for the statistical significance limit.

\section{Results}

A total of 336 EDRs were included in the study, of which 100 (29.8\%) were female and 236 (70.2\%) were male. $45.4 \%$ of EDRs are in the age range $25-27$, while $27.6 \%$ are in the age range 28 - 
30. 23.3\% of the EDRs included in the study were in their first year, $29.9 \%$ were in their second year and $24.4 \%$ were in their third year. Furthermore, $85.1 \%$ of the EDR's were employed at public universities, $4.9 \%$ at private/foundation universities, and $10.1 \%$ at educational research hospitals. The general characteristics and training information of the resident is included in the study are given in Table 1 . The average age of the residents in the study was calculated as $28.8 \pm 3.4$. There was no statistically significant difference in age averages when we examined them based on gender $(p=0.189)$. The average age of the female residents included in the study was $28.5 \pm 3.1$, while the average age of the male residents was $29.0 \pm 3.5$.

\begin{tabular}{|c|c|c|}
\hline Variables & $n$ & $\%$ \\
\hline \multicolumn{3}{|l|}{ Gender } \\
\hline Woman & 104 & 29.9 \\
\hline Man & 244 & 70.1 \\
\hline \multicolumn{3}{|l|}{ Age } \\
\hline 25-27 age & 158 & 45.4 \\
\hline 28-30 age & 96 & 27.6 \\
\hline 31-33 age & 59 & 17.0 \\
\hline 34-36 age & 25 & 7.2 \\
\hline $37-43$ age & 10 & 2.9 \\
\hline \multicolumn{3}{|l|}{ Working institution } \\
\hline Public university & 296 & 85.1 \\
\hline Private/foundation university & 17 & 4.9 \\
\hline Educational research hospital & 35 & 10.1 \\
\hline \multicolumn{3}{|l|}{ Residency period } \\
\hline 1 & 81 & 23.3 \\
\hline 2 & 104 & 29.9 \\
\hline 3 & 85 & 24.4 \\
\hline 4 & 62 & 17.8 \\
\hline 5 & 16 & 4.6 \\
\hline \multicolumn{3}{|c|}{ The number of residents in the department } \\
\hline 5-13 resident & 19 & 5.7 \\
\hline 14-22 resident & 176 & 52.4 \\
\hline 23-31 resident & 126 & 37.5 \\
\hline 32-38 resident & 15 & 4.5 \\
\hline \multicolumn{3}{|c|}{ Total number of instructors in the department } \\
\hline 0 or undeclared & 1 & 0.3 \\
\hline $1-3$ & 13 & 3.9 \\
\hline $4-6$ & 250 & 74.4 \\
\hline $7-10$ & 49 & 14.6 \\
\hline $11+$ & 23 & 6.8 \\
\hline \multicolumn{3}{|l|}{ n: Number } \\
\hline
\end{tabular}

They stated that $96.3 \%$ were held according to whether a regular training meeting was held. In evaluating the training received by EDRs in their institutions, they evaluated $42.2 \%$ as medium. They evaluated the training activities as 39.9\% in hours/amount and the training activities as $41.7 \%$ in terms of type/content. In the questionnaire applied, they stated that $85.9 \%$ of EDRs did not apply assistant exams in their institutions and $60 \%$ did not believe in the necessity of the exam. They also stated that $89 \%$ of EDRs did not have an assistant certificate. It has been determined that it is at a medium level of $38 \%$ in terms of "numerical sufficiency of the trainer staff". It has been determined that EDRs are the sources of information, mostly of classical books, consultant physicians and trainers, respectively. They found that the duration of rotation in other branches was moderate (37.1\%) and that the contribution of rotations to clinical practice was moderate (40.5\%) (Table 2 ).

There was a significant difference between the patient care rate of the department and the institution of education according to the relationship between the institution of education and the rates of Service-research-education $(p=0.006)$. There was a significant difference between the education rate in the department and the institution of education $(p<0.001)$. There was no significant difference between the research rate in the department and the educational institution $(p=0.238)$ (Table 3).

The educational level at the institution was related to the educational staff $(p<0.001)$. The perception of conformity of the duration of rotations in other branches and the perception of the contribution of rotations to clinical practice and the perception of the quality of training in the institution affects one another $(p<0.001)$. There was no significant difference between the number of patients and the level of education when comparing the number of daily patients and the total number of instructors $(p=0.708)$. However, there was a significant difference between the level of education and the total number of instructors $(p=0.003)$ (Table 4).

\section{Discussion}

The learning environment encompasses both the student's written curriculum and the curriculum that expresses the social factors of medical practice, which include relationships, values, and behaviors encountered in clinical practice. Active training is a critical part of the specialty training to become an autonomous physician. One-on-one training, training on the patient creates degree autonomy in a short time (5). Physicians provide effective, patient care at the same time, while also performing the duties of evaluating and addressing the learning needs of residents and medical school students (6). The fact that male participants 
Table 2. Educational data of the EDRs included in the study

Is there a regular training session every week?

\begin{tabular}{|l|l|l|}
\hline Yes & 335 & 96.3 \\
\hline No & 13 & 3.7 \\
\hline
\end{tabular}

Evaluate the training you have received at your institution

\begin{tabular}{|l|l|l|}
\hline Not adequate & 89 & 25.6 \\
\hline Intermediate level & 147 & 42.2 \\
\hline Adequate & 112 & 32.2 \\
\hline
\end{tabular}

Evaluate training activities in hours/quantity

\begin{tabular}{|l|l|l|}
\hline Not adequate & 106 & 30.5 \\
\hline Intermediate level & 139 & 39.9 \\
\hline Adequate & 103 & 29.6 \\
\hline \multicolumn{2}{|l|}{ Evaluate educational activities as type/content } \\
\hline Not adequate & 76 & 21.8 \\
\hline Intermediate level & 145 & 41.7 \\
\hline Adequate & 127 & 36.5 \\
\hline
\end{tabular}

Do you have a resident exam at your clinic?

\begin{tabular}{|l|l|l|}
\hline Yes & 49 & 14.1 \\
\hline No & 299 & 85.9 \\
\hline
\end{tabular}

Do you believe in the necessity of a resident exam?

\begin{tabular}{|l|l|l|}
\hline Yes & 139 & 40 \\
\hline No & 209 & 60 \\
\hline
\end{tabular}

Do you have a resident report card in your clinic?

\begin{tabular}{|l|l|l|}
\hline Yes & 38 & 11 \\
\hline No & 310 & 89 \\
\hline Is the training staff numerically adequate?
\end{tabular}

Is the training staff numerically adequate?

\begin{tabular}{|l|l|l|}
\hline Not adequate & 94 & 27 \\
\hline Intermediate level & 132 & 38 \\
\hline Adequate & 121 & 35 \\
\hline
\end{tabular}

Who/where do you get the most information from in your field?

\begin{tabular}{|l|l|l|}
\hline Senior Resident & 10 & 2.9 \\
\hline Trainers & 84 & 24.1 \\
\hline Classic books & 133 & 38.2 \\
\hline Consultative physician & 88 & 25.2 \\
\hline Internet/digital resources & 33 & 9.6 \\
\hline Are your rotations and times in other branch adequate?
\end{tabular}

Are your rotations and times in other branches adequate?

\begin{tabular}{|l|l|l|}
\hline Not adequate & 113 & 32.5 \\
\hline Intermediate level & 129 & 37.1 \\
\hline Adequate & 106 & 30.4 \\
\hline
\end{tabular}

Do you find the contribution of rotations in other branches to your clinical practice adequate?

\begin{tabular}{|l|l|l|}
\hline Not adequate & 109 & 31.3 \\
\hline Intermediate level & 141 & 40.5 \\
\hline Adequate & 98 & 28.2 \\
\hline EDR: Emergency department residents
\end{tabular}

were numerically greater than female participants in our study supports the belief that men preferred medical schools more. In other studies, the proportion of male students was higher than female students $(7,8)$. According to the 2019 examination for specialty in medicine in Turkey (TUS) results, $58.26 \%$ of the candidates applying for emergency medicine specialty training were placed in state universities, 3.3\% in foundation universities, and $38.44 \%$ in educational research hospitals (9). $85.1 \%$ of the respondents continue to study in public universities, $10.1 \%$ in educational-research hospitals, and $4.9 \%$ in foundation universities.

In our study, it is observed that the perception of the educational quality in foundation universities differs positively compared to other institutions. In a study comparing burnout syndrome of EDRs in medical school hospitals and educational research hospitals, it is known that state institutions are intensive in terms of workload (10). Considering that regular functioning will be disrupted even with specialty training under heavy workload, it may result in the context in expert candidates not seeing the education they have received as "adequate". It may also be possible for residents who are likely to experience burnout syndrome to negatively evaluate their environment. In a survey conducted by the İstanbul Medical Chamber, specialty training working group in 2001, which in the views of EDRs trained in educational hospitals and universities in Istanbul were evaluated, "Is there a structured resident training program in your institution? $64.1 \%$ of answers to the question: there is, applied" (11).

$70.6 \%$ of EDRs who continue their specialty training at foundation universities have stated that the duration and content of their education are adequate, $28.0 \%$ of EDRs in public universities are adequate and $22.9 \%$ of EDRs in educational research hospitals have declared that the duration of their education is adequate. A study found that the duration of training in the fields was mostly adequate and concluded that structured training programs were implemented in a planned and functional manner (12). In another study, it was found that EDRs who were tested with different methods on "approach to multiple trauma patients" were more successful than those who were supported with visual training materials (13). The residents who are rich in content and visually filled and have enough time training for the field can be evaluated to be more successful in practice. The workload on public institutions can cause trainers to be unable to how enough attention, time to residents. As the number of emergency medical professionals increases, the workload will decrease, so it can be considered that there will be a decrease in overall dissatisfaction. However, the balance of education and practice can be well established and the binding of certain rules can be useful in terms of standardization. 
Table 3. Patient care-education-research relationship with the institution of education

\begin{tabular}{|l|l|l|l|l|}
\hline & Public university & $\begin{array}{l}\text { Private/foundation } \\
\text { university }\end{array}$ & $\begin{array}{l}\text { Educational research } \\
\text { hospital }\end{array}$ & $\mathbf{p}$ \\
\hline Patient care ratio & $48.5 \pm 18.8$ & $34.1 \pm 11.4$ & $50.1 \pm 18.9$ & $\mathbf{0 . 0 0 6}$ \\
\hline Research ratio & $31.8 \pm 12.3$ & $44.7 \pm 11.8$ & $31.6 \pm 12.8$ & $<0.001$ \\
\hline Education ratio & $19.5 \pm 10.2$ & $23.5 \pm 10.1$ & $18.4 \pm 11.9$ & 0.238 \\
\hline
\end{tabular}

\begin{tabular}{|c|c|c|c|c|}
\hline \multirow[t]{2}{*}{ Variables } & \multicolumn{3}{|c|}{ The level of education you receive at your institution } & \multirow[t]{2}{*}{ p } \\
\hline & Not adequate & Intermediate level & Adequate & \\
\hline \multicolumn{5}{|c|}{ Is the training staff numerically adequate? } \\
\hline Not adequate & $65(73.0)$ & $27(18.4)$ & $2(1.8)$ & \multirow{3}{*}{$<0.001$} \\
\hline Intermediate level & $24(27.0)$ & $88(59.9)$ & $21(18.8)$ & \\
\hline Adequate & $0(0.0)$ & $32(21.8)$ & $89(79.5)$ & \\
\hline \multicolumn{5}{|c|}{ Are your rotations and times in other branches sufficient? } \\
\hline Not adequate & $60(67.4)$ & $47(32.0)$ & $6(5.4)$ & \multirow{3}{*}{$<0.001$} \\
\hline Intermediate level & $23(25.8)$ & $74(50.3)$ & $32(28.6)$ & \\
\hline Adequate & $6(6.7)$ & $26(17.7)$ & $74(66.1)$ & \\
\hline \multicolumn{5}{|c|}{ Do you find the contribution of rotations in other branches to your clinical practice sufficient? } \\
\hline Not adequate & $62(69.7)$ & $39(26.5)$ & $8(7.1)$ & \multirow{3}{*}{$<0.001$} \\
\hline Intermediate level & $25(28.1)$ & $83(56.5)$ & $33(29.5)$ & \\
\hline Adequate & $2(2.2)$ & $25(17.0)$ & $71(63.4)$ & \\
\hline Daily number of patients (mean \pm SD) & $494.71 \pm 278.17$ & $473.33 \pm 324.22$ & $457.46 \pm 332.16$ & 0.708 \\
\hline Total trainers (mean \pm SD) & $4.71 \pm 2.04$ & $5.37 \pm 2.96$ & $5.84 \pm 2.66$ & 0.003 \\
\hline
\end{tabular}

Over $70 \%$ of EDRs who continue their education in institutions have declared that the resident exam is not applied. It can also be said that resident exams have not generally become a settled practice. The study published in 2011 on the specialty training period suggests the application of a modified resident report card instead of the current resident report card (14). In the proposed model, students of expertise are observed and evaluated by trainers. It is suggested that the number of observations and evaluations performed, the short evaluation notes and development plans of the trainers and residents should be included in the report card. The opinion grades given to the exam that is not performed and the resident report card that is not applied can negatively affect the perception of quality and competence of the education. Ensuring that the quality of education is given to the same standard without changing from institution to institution is an expectation of the beneficiaries of this service. It may be easier for physicians who have successfully graduated from certain standards of education and gained the title of the specialist physician to fulfill the requirements of their expertise with self-confidence.
When the numerical adequacy of the educational staff is investigated, there is a significant difference between the institutions. In the 2006 study, 77.1\% of Ege University Faculty of Medicine (EUFM) residents and $64.5 \%$ of Adnan Menderes University Faculty of Medicine (AMUFM) residents stated that the number of trainers was sufficient (4). The fact that the field of ED is new and not enough experts have been trained yet is thought to have affected the existing data. They may also prefer foundation universities, where the conditions of existing emergency medical specialists are better due to the heavy of working conditions in public institutions. The workloads of trainers that differ from institution to institution can cause the time allocated to the training to differ. This can also cause a difference in perception.

According to the responses given, the source of educational information (senior resident, trainer, consultant doctor) was $52.3 \%$ and via classical-digital book-internet was $47.7 \%$. In a study conducted at Dokuz Eylül and Ege University Faculty of Medicine, participants rated the scientific and educational skills of the individuals who trained themselves as $70.4 \%$ and $72.2 \%$. 
"From whom do you learn the most about your field? The most answers to the question were "from the faculty members" and "by reading books" (11). In a study conducted with thoracic surgery residents, $67.4 \%$ of trainers and $32.6 \%$ of classical books were cited as sources of Information (15). The sources of information are similar to the study mentioned. Due to the lack of the number of trainers in public institutions, EDR may be not able to care enough. Taking parts of EDR in scientific research throughout education, to evaluate scientific evidence and continuity of this is extremely necessary for educational processes (16).

Duration adequacy of rotations in other branches did not differ significantly between institutions. However, when asked about the contribution of rotations in other branches to clinical practice, significant differences were determined between institutions. In a study conducted, $28.1 \%$ of EUFM residents and $20.8 \%$ of ADUFM residents stated that they found the education taken in rotations adequate (4). A 2009 study indicated that the effect of rotations on emergency medicine specialist candidates was not desirable (17). In another study, $18 \%$ of emergency medicine residents stated their contribution level to the clinical practice of rotations as 0 (18). The patient-resident balance needs to be well planned, as public institutions assume the bulk of the burden in the health sector. Specialization training should include a structured training program, knowledge-skill-attitude goals, suggestions on how to learn theoretical and practical information, basic reading resources related to the field of expertise, mastering criteria related to the skill to be acquired (how many times to learn if the skill is applied), etc. (16).

\section{Conclusion}

As a result, EDRs should be able to receive specialized training with a smaller number of groups rather than crowds. When determining the capacities of educational institutions, the most appropriate capacities should be determined, not the maximum. It may be necessary to adjust the training infrastructures of the educational institutions according to the specialist training. It may be appropriate to go to standardization in specialty training to train the residents well. In general, although they are suitable for specialty training, the institutions within the staff shortage should be given expert candidates according to their staff. It will be related to the training that the candidates of experts adopt the educational institutions they graduated from. Therefore, satisfaction levels should be increased to increase the preference of educational institutions.

\section{Ethics}

Ethics Committee Approval: The study was conducted after the approval of the Clinical Research Ethics Committee of Mersin University Rectorate (date: 09.01.2017 and number: 2019/03).
Informed Consent: It is a survey study; It was obtained.

Peer-review: Extenally peer-reviewed.

\section{Authorship Contributions}

Concept: K.E.A., A.K., Y.U., Design: K.E.A., A.K., Y.U., Data Collection or Processing: K.E.A., A.K., Y.U., S.B.B., Analysis or Interpretation: K.E.A., A.K., S.E., Literature Search: K.E.A., A.K., Writing: K.E.A., A.K., S.B.B.

Conflict of Interest: No conflict of interest was declared by the authors.

Financial Disclosure: The authors declared that this study received no financial support.

\section{References}

1. Yilmaz S, Akkaya VB. Problems and Proposals of Their Solutions in Dermatology Residency Training: A Survey of Residents' Opinions in Turkey. Journal of skin diseases and syphilis. 2009;43:10-4

2. The International Federation for Emergency Medicine (IFEM). Available at: https://www.ifem.cc/about-us/, access date: 15/08/2019.

3. Kösemehmetoğlu K, Gümüșkaya Öcal B, Coșkunoğlu EZ, Çulha İ, Çiçek AF, Daglar E, et al. Resident training in pathology: From resident's point of view. Turk J Pathol. 2008;24:21-6.

4. Gültekin BK, Söylemez A, Dereboy IF, Çiçek C.Residency Training at Medical Schools of Ege and Adnan Menderes Universities: The Residents'Perspective. ADU Medical Faculty Journal. 2006;7:17-21.

5. Tomlinson S, Carney MM, Wolff M. Advances in Medical Education and Implications for the Pediatric Emergency Department. Pediatr Clin North Am. 2018;65:1221-7

6. Farrell SE, Hopson LR, Wolff M, Hemphill RR, Santen SA. What's the Evidence: A Review of the One-Minute Preceptor Model of Clinical Teaching and Implications for Teaching in the Emergency Department. J Emerg Med 2016;51:278-83.

7. Alper Z, Özdemir H. Some Socio-Demographic Properties and Profession Perspectives of Students who Preferred Uludağ University Faculty of Medicine. Uludağ Üniv Tıp Fak Derg. 2004;30:93-6

8. Köksal S, Vehid S, Tunçkale A, Cerçel A, Erginöz E, Kaypmaz A, et al. The attitudes of Cerrahpasa Faculty of Medicine students about medical training and post-graduation. J Med. 1999, 30:247-314.

9. TUS: entrance exam for specialty training in medicine, https://www.osym gov.tr/TR,15733/2019-tus-1-donem-genel-yerlestirme-sonuclarina-iliskinsayisal-bilgiler.html, accessed: 21/10/2019.

10. Ersoy S, Kavalci C, Yel C, Yilmaz F, Kavalci G, Aslan Ö. Comparison of burnout levels of Emergency Medicine residents working in Medical School hospitals and the Ministry of Health Educational Research hospitals. Med J. 2014;14:41-5.

11. Istanbul Medical Chamber, Speciality Training Working Group. Available at: www.istanbul.org.tr, 21.08.2005 (accessed: 10.10.2019).

12. Ciçek C, Terzi C, Solak A, Arsu G, Batu J, Vatansever K, et al. Universite hastanelerinde temel bilimler alaninda uzmanlik eğitimi: tipta uzmanlik öğrencisi bakiş açisi ile [Specialist training in basic sciences in university hospitals: specialist resident perspective]. Mikrobiyol Bul. 2005;39:491-501.

13. Sarıhan A, Oray NC, Güllüpınar B, Yanturali S, Atilla R, Musal B. The comparison of the efficiency of traditional lectures to video-supported 
lectures within the training of the Emergency Medicine residents. Turk J Emerg Med. 2016 ;16:107-11.

14. Gülpınar MA. Guide to developing a specialized training period and framework Training Program. World Med Educ. 2011;29-59.

15. Akçam TI, Çağrıcı U, Çakan A, Turhan K, Özdil A. What do chest surgery residents think of their surgical training? J Cardiovasc Surg. 2012;20:107-10.

16. Tailor C. Speciality Training In Medicine. I. Training in Medicine, Programming Practice Evaluation Workshop, 5-10 November 2004, Ankara. Available at: www.ttb.org.tr/udkk, 19.08.2005.
17. Aksay E, Sahin H, Kiyan S, Ersel M. Current status of emergency residency training programs in Turkey: after 14 years of experience. Eur J Emerg Med. 2009;16:4-10.

18. Sezik S, Aksay E, Temizyürek Z, Bilge A. The opinions of specialized students in emergency medicine on rotation effectiveness: a national survey study. Turk J Emerg Med. 2012;1:8-14. 